\title{
Results of workplace drug testing in Norway
}

\author{
Hilde Marie Erøy Lund ${ }^{1}$, Stig Tore Bogstrand ${ }^{1,2}$ and Asbjørg Solberg Christophersen ${ }^{1}$ \\ 1) Norwegian Institute of Public Health, Division of Forensic Medicine and Drug Abuse Research, \\ PO Box 4404 Nydalen, N-0403 Oslo, Norway \\ 2) Oslo University Hospital, Division of Critical Care, Department of Research and Development, N-0407 Oslo, Norway \\ Correspondence: Hilde Marie Erøy Lund, E-mail: hier@fhi.no Telephone: +4721077862
}

\begin{abstract}
Workplace drug testing is less common in Norway than in many other countries. During the period from 2000-2006, 13469 urine or blood samples from employees in the offshore industry, shipping companies and aviation industry were submitted to the Norwegian Institute of Public Health for drug testing. The samples were analysed for benzodiazepines, illicit drugs, muscle relaxants with sedating properties, opioids and z-hypnotics. In total, $2.9 \%$ of the samples were positive for one or more substances. During the study period the prevalence decreased for morphine (from 1.9\% to $1.1 \%$ ) and increased for amphetamine (from $0.04 \%$ to $0.6 \%$ ), clonazepam (from $0 \%$ to $0.1 \%$ ), methamphetamine (from $0.04 \%$ to $0.6 \%$ ), nitrazepam (from $0 \%$ to $0.4 \%$ ) and oxazepam (from $0.5 \%$ to $1.3 \%$ ) ( $\mathrm{p}<0.05)$. There was no significant change in prevalence for the other substances included in the analytical programme. Illicit drugs were significantly associated with lower age (OR: $0.93, \mathrm{p}<0.05)$. This study found low prevalence of drugs among employees in companies with workplace drug testing programmes in Norway.
\end{abstract}

\section{INTRODUCTION}

Approximately one half of Europeans participating in rehabilitation programmes are employees (1). Illicit drugs can cause accidents, violence and suicidal behaviour with consequences like absence from work, accidents, reduced performance, and eventually unemployment. In addition illicit drug use is co-occuring with psychiatric disorders, and injection can spread infectious diseases like Hepatitis B, C and HIV $(2,3)$. Psychoactive drugs can have effects on psychomotor function, reaction time, coordination, alertness, vision, risk taking and aggressiveness $(2,4)$ which can have direct consequences in certain workplace settings.

There are several factors to consider when results from workplace drug testing are being discussed (5). The type of control such as pre- or post-employment, and random versus forced testing can affect the results. Announced pre-employment testing would be expected to give fewer positive biological samples than unannounced random testing $(1,5)$. The biological matrix to be analysed (blood, urine, hair, saliva sweat), substances considered and applied values for positive vs. negative determination (cut-off values) will in addition greatly influence the results. Different matrixes have different detection times (6); drugs can be detected for hours in blood, for hours to days or weeks in urine depending on the substance, and for days to weeks in sweat. Hair can be used to detect drugs that were taken from weeks and up to more than a year ago $(6,7)$. Analytical strategies can differ based on the compound's chemical properties (8) and concentration range in a given biological medium. A lower cut-off value will extend the detection window, and may result in increasing prevalence. It is therefore difficult to compare results from the different countries as laboratories may be operating with different cut-off values.

Workplace drug testing in Europe has been reviewed (9), but there is little information about Norwegian employees (10). Prevalence rates of non-alcohol drugs varies between less than one and up to five percent in European workplace testing studies (9). In the US, testing is more widespread (11), and the prevalence has decreased from $13.6 \%$ in 1988 to $3.6 \%$ in $2009 / 2010$ (12).

Gjerde and co-workers conducted a pilot study of Norwegian employees to obtain information about the use of alcohol and drugs in the Norwegian workplace (10). 526 employees participated in the study and the total participation rate was $82 \%$. The sampling comprised of self-report of drug use and a saliva sample. The biological samples were analysed for alcohol and psychoactive medicinal and illicit drugs. The combination of self-report and analytical results from saliva indicated that medicinal or illicit drugs had been used during the last 48 hours by $5.1 \%$ and $1.7 \%$ of the participants, respectively. Only $4.2 \%$ and $0.4 \%$ reported the use of the corresponding drugs in the questionnaire.

The aim of this study was to describe the prevalence of psychoactive drug use among workers in safetycritical positions in the offshore, shipping and aviation industry participating in a workplace testing programme.

\section{MATERIALS AND METHODS}

\section{Study design, setting and participants}

During the period 2000-2006, 13469 samples of urine or blood from random workers in critical positions in the offshore business, shipping business, and aviation industry were submitted to the Norwegian Institute of 
Public Health for drug testing. It is theoretically possible that some persons were tested more than once, but such information was not available and thus not taken into account. The testing was mandatory, random and done post-employment and according to a contract between the employee and the employer as a part of the drug testing programme in the company. Testing was performed without preliminary warning.

\section{Data sources and variables}

The urine samples were analysed for benzodiazepines (alprazolam, clonazepam, diazepam, fenazepam, flunitrazepam, lorazepam, midazolam, nitrazepam, oxazepam), illicit drugs (6-acetylmorphine (6-AM)/heroine, amphetamine, cocaine, ecstasy (MDMA), methamphetamine, $\Delta 9$-tetrahydrocannabinol-COOH (THC$\mathrm{COOH}$, cannabis)), muscle relaxants with sedating properties (carisoprodol, meprobamate), opioids (buprenorphine, codeine, dextropropoxyphene, ethylmorphine, methadone, morphine), and sleeping agents (zolpidem, zopiclone). Heroine intake is proven by analysis of 6-AM in blood or urine, 6-AM is a metabolite of heroine that later is metabolised into morphine in vivo (13). The results were merged before statistical analysis so that positive results represent positive findings from both urine and blood samples. Preliminary screening was performed with the enzyme multiplied immunoassay technique (EMIT) to detect substance groups of drugs in the samples, and positive results were confirmed by chromatographic methods (gas and liquid chromatography with mass spectrometric detection).

\section{Statistical methods}

Statistical analyses were carried out using PASW $^{\circledR}$ Statistics (SPSS version 17). Associations between positive samples and employee characteristics were analysed in bi-variate cross tables for the substances. Pearson's Chi-square statistics were used to assess statistical significance. The factors associated with the group of substance detected were analysed using multiple logistic regression to calculate odds ratio (OR) and $95 \%$ confidence intervals (CI). The level of statistic significance was set as $p<0.05$ or $p<0.01$. An independent $t$-test was performed to compare the mean age of persons with a negative test result to the mean age of persons with at least one positive test result for each substance group, significance level $\mathrm{p}<0.01$.

\section{Ethics}

The material was taken from an existing data base, and the dataset was completely anonymous.

\section{RESULTS}

\section{Participants}

13469 samples were analysed over a period of 7 years. $1356(10.1 \%)$ of the samples were collected without information about the person's gender, 544 (4.5\%) samples were from women, and 11542 (95.5\%) samples were from men. $63.6 \%$ of the participants were under 50 years (Table 1), and the mean age of the participants were 41.4 years. A total of $2.9 \%$ of the samples were positive for one or more of the tested substances (Table 2).

\section{Opioids}

The prevalence of opioids varied from $1.9 \%$ to $1.1 \%$ during the period 2000-2006. The trend was decreasing (OR:0.89, 95\% CI: 0.82-0.96, $\mathrm{p}<0.05$ ). Opioids were the group of drugs that was found most frequently in this study (Table 2). $1.5 \%$ of the samples were opioid positive, and $48.3 \%$ of the positive samples were positive for an opioid. The prevalence of morphine had a significant reduction during this time period, the prevalence decreased from $2 \%$ in 2000 to $1.1 \%$ in $2006(\mathrm{p}<0.05)$. There was no significant difference in the prevalence of opioids for age groups or gender as presented in Table 3. The prevalence of the tested opioids was: $1.5 \%$ for morphine $(n=201), 1.0 \%$ for codeine $(n=128), 0.2 \%$ for ethylmorphine $(n=23)$, $0.04 \%$ dextropropoxyphene $(n=5)$, and $0.01 \%$ for buprenorphine $(n=1)$. Since codeine is metabolised to morphine, some samples with morphine detected (with or without codeine) may come from codeine use, and not from intake of morphine.

\section{Benzodiazepines}

The prevalence of benzodiazepines varied from $0.5 \%$ to $1.4 \%$ during the period from $2000-2006$. The trend was increasing (OR: 1.12, 95\% CI: 1.01-1.24, $\mathrm{p}<0.05$ ). Statistical bivariate tests showed that the increased prevalence mainly was due to the increase of clonazepam, nitrazepam and oxazepam $(\mathrm{p}<0.05)$. The other benzodiazepines did not have a significant change in prevalence during this time period. There was no significant difference between findings in samples representing different age groups or for gender. The prevalence of the tested benzodiazepines was: $0.8 \%$ for oxazepam $(n=113), 0.7 \%$ for diazepam $(n=92), 0.1 \%$ for nitrazepam $(n=12), 0.04 \%$ for clonazepam $(n=6), 0.04 \%$ for flunitrazepam $(n=6), 0.02 \%$ for alprazolam $(n=3)$, and $0.01 \%$ for lorazepam $(n=1)$.

\section{Illicit drugs}

The prevalence of the illicit drugs varied from $0.6 \%$ in 2000 to a top of almost $1.6 \%$ in 2003, and a prevalence of $1 \%$ in 2006 . The trend was increasing (OR: 1.16, 95\% CI: $1.05-1.28, \mathrm{p}<0.05)$. Cannabis was the illicit drug with highest prevalence and $0.8 \%$ of the samples were positive for the THC-metabolite THC-COOH which is detected in urine samples. The year with highest prevalence of cannabis was 2003 (1.4\%), and a prevalence of about $0.5 \%$ was found in 2000 and 2006 . There was no significant change in the prevalence of cocaine, heroine, or ecstasy, while amphetamine and methamphetamine increased significantly $(p<0.05)$. Twenty-two of the 36 amphetamine positive samples 
Table 1. Sample characteristics and prevalence of drug use by gender, age and year.

\begin{tabular}{|c|c|c|c|c|c|c|}
\hline & $\mathrm{n}$ & $\begin{array}{c}\mathrm{n}=13469 \\
(\%)\end{array}$ & $\begin{array}{c}\text { Negative } \\
(\%)^{\mathrm{a}}\end{array}$ & $\begin{array}{l}\text { Benzodiaze- } \\
\text { pines }(\%)\end{array}$ & $\begin{array}{c}\text { Illicit } \\
\text { drugs (\%) }\end{array}$ & Opioids (\%) \\
\hline \multicolumn{7}{|l|}{ Gender $^{\mathrm{b}}(\mathrm{n}=12086)$} \\
\hline Men & 11542 & 95.5 & $96.8^{\mathrm{NS}}$ & $0.85^{\mathrm{NS}}$ & $0.98^{\mathrm{NS}}$ & $1.59^{\mathrm{NS}}$ \\
\hline Women & 544 & 4.5 & 98.2 & 0.74 & 0.92 & 0.55 \\
\hline Mean age $(n=12113)$ & 41.4 & & $41.2 * *$ & $41.4^{\mathrm{NS}}$ & $32.3 * *$ & $41.0^{\mathrm{NS}}$ \\
\hline \multicolumn{7}{|l|}{ Age group $^{b}(\mathrm{n}=12113)$} \\
\hline $15-29$ & 2745 & 22.7 & $95.8 * *$ & $0.87^{\mathrm{NS}}$ & $2.33 * *$ & $1.79^{\mathrm{NS}}$ \\
\hline $30-39$ & 2964 & 24.5 & 97.3 & 0.71 & 0.64 & 1.42 \\
\hline $40-49$ & 2858 & 23.6 & 97.2 & 0.94 & 0.77 & 1.26 \\
\hline $50-59$ & 3090 & 25.5 & 97.0 & 0.84 & 0.32 & 1.78 \\
\hline $60-69$ & 456 & 3.8 & 97.1 & 1.10 & 0 & 1.32 \\
\hline \multicolumn{7}{|l|}{ Year $(n=13469)$} \\
\hline 2000 & 2551 & 18.9 & $97.0^{\mathrm{NS}}$ & $0.51^{\mathrm{NS}}$ & $0.55 * *$ & $1.92^{\mathrm{NS}}$ \\
\hline 2001 & 2197 & 16.3 & 96.7 & 0.96 & 0.91 & 1.82 \\
\hline 2002 & 2004 & 14.9 & 97.0 & 0.95 & 0.75 & 1.50 \\
\hline 2003 & 1549 & 11.5 & 96.1 & 0.97 & 1.55 & 1.94 \\
\hline 2004 & 1701 & 12.6 & 97.5 & 0.41 & 1.12 & 0.88 \\
\hline 2005 & 1548 & 11.5 & 96.4 & 1.16 & 1.36 & 1.29 \\
\hline 2006 & 1919 & 14.2 & 97.0 & 1.41 & 1.04 & 1.09 \\
\hline \\
\hline & & \multicolumn{5}{|c|}{ b Age and gender were unknown for some participants } \\
\hline \multicolumn{7}{|c|}{$\begin{array}{l}\text { c An independent t-test was performed to compare the mean age of persons with a negative test result to the mean age of persons } \\
\text { with at least one positive test result }\end{array}$} \\
\hline \multicolumn{7}{|c|}{$* * \mathrm{p}<0.001$} \\
\hline
\end{tabular}

Table 2. Positive tests and persons by type of substance $(\mathrm{n}=13$ 469).

\begin{tabular}{lcc}
\hline Drug classes & \% of all tests & $\%$ of all positive tests \\
\hline Benzodiazepines & 0.9 & 30.5 \\
Illicit drugs & 1.0 & 33.8 \\
Opioids & 1.5 & 52.0 \\
Total \% of all workers & 2.9 & \\
\hline
\end{tabular}

Table 3. OR with $95 \%$ confidence intervals for the positive tests: multiple regression with age, gender and year.

\begin{tabular}{lccc}
\hline & Benzodiazepines & Illicit drugs & Opioids \\
\hline Age & $1.00(0.98-1.02)$ & $0.93(0.92-0.95)^{*}$ & $1.00(0.99-1.01)$ \\
Gender & $1.15(0.42-3.17)$ & $1.78(0.72-4.40)$ & $2.88(0.91-9.11)$ \\
Year & $1.12(1.01-1.24) *$ & $1.16(1.05-1.28)^{*}$ & $0.89(0.82-0.96)^{*}$ \\
\hline${ }^{*}<0.05$ & & &
\end{tabular}

were also positive for methamphetamine. This may indicate that methamphetamine was the abused drug, as methamphetamine is metabolised to amphetamine in vivo. Concurrent use can however not be ruled out. Heroine use was demonstrated by the positive finding of the metabolite 6-AM in 10 samples.

There was a significant correlation between age and prevalence of illicit drugs with an increased risk for a positive sample from persons with lower age (OR:
0.93, 95\% CI: 0.92-0.95, $\mathrm{p}<0.05)$. Workers under 30 had the highest prevalence, while workers over 60 years did not have any positive samples for illicit drugs. There was no significant association for gender regarding the prevalence of illicit drugs. The prevalence of the tested illicit drugs was: $0.3 \%$ for amphetamine $(n=36), 0.2 \%$ for methamphetamine $(n=22), 0.1 \%$ for heroine $(n=10), 0.03 \%$ for ecstacy $(n=4)$, and 0.03 for cocaine $(n=4)$.

\section{Sleeping agents}

No zolpidem or zopiclone was found in this dataset.

\section{Discussion}

This study of workplace drugs testing in Norway from 2000-2006 showed that a marginal portion, $2.9 \%$, of the samples were positive of one or more substances. Other studies have found higher numbers $(9,10,12)$. Opioids were found most frequently and $1 / 3$ of the positive samples were positive for a benzodiazepine and/or an illicit drug. Prescription drugs (opioids and benzodiazepines) were found more frequently than illegal drugs. Use of such drugs, even within the prescribed dosage regimen may increase the risk of accidents in traffic, and correspondingly at the workplace $(14,15)$. Higher risks at elevated dosage are expected, and use of prescription drugs in combination with illegal drugs can be indicative of non-prescribed use. There were no significant associations between drug 
findings and genders. Illicit drugs were significantly more frequent at a lower age.

The prevalence rate of positive samples in this study matches the prevalence rates in the review of European workplace testing studies $(1,9)$. The prevalence rate was, however, lower than in the workplace study by Gjerde and colleagues (10), but the results were not directly comparable as the prevalence was surveyed by self-report in addition to oral fluid, and covered intake during the last 24 or 48 hours. Another Norwegian study of use of alcohol, psychoactive medicinal drugs and illicit drugs in a representative selection of drivers in Norwegian road traffic showed that alcohol and drugs were detected in $5.7 \%$ of the drivers (16). Medicinal drugs were found in $4.5 \%$ and illicit drugs in $1.1 \%$ of the samples. In the study of drivers, illicit drugs were found more frequently in samples from younger drivers.

The workplace drug testing data from this study showed a lower prevalence than the testing of Norwegian drivers from 2005-2006. Comparison between testing of random drivers and at the workplace must, however, be done with caution as these populations are not identical. The literature points to the fact that when workplace drug testing is in place, the prevalence decreases (1). One possible explanation can be that workplace drug testing programmes lead to less drug use. Another explanation can be that the testing it-self influence the testing population towards a selection of persons not using drugs. The decreasing prevalence of drug positive samples in the US from 1998-2009/2010 may in fact indicate that employees who use illicit drugs to a larger degree than non users, have been excluded from the US labour market these last years (12). Other possible explanations for the differences is that the businesses tested was not representative for the normal driving population in Norway, or that the analysis of saliva was more comprehensive than the analysis of urine. The participants in this study had safety-critical positions at their workplace. This type of work usually has a high demand for alertness and physical requirements associated with better health than the regular work-force. A lower prevalence in this study compared to the Norwegian drivers can also be the result of fewer drugs tested in this study. When the analytical programme includes more compounds, the prevalence of positive tests is expected to increase.

The most frequent drugs in this study were the opioids. Norwegian workers in this sample seemed to abuse cannabis to a smaller extent than workers in other countries. Cannabis is the most widely used illicit drug revealed in workplace drug testing $(7,9,12,17$, 18). Possibly the businesses tested in Norway use less cannabis than the general work-force, however other sources similarly point at lower cannabis use in Norway (19). The trend of increasing prevalence of amphetamines was apparent in this study as well as in other studies $(12,20,21)$.

\section{Strengths/limitations}

The strengths of this study were that the testing was done unannounced, a large number of participants were included, and all the employee samples were tested at the same laboratory during the time period of 20002006. Limitations of the study was that significantly more men than women were tested, a limited area of the work-force was included, urine samples only indicate drug use at some time and give limited information of the dose and time of drug intake (22), and there was no information about prescribed drug use. The above mentioned factors make the data hard to generalise to the general population. Positive findings of medicinal drugs could be a result of prescribed drug use, with no reduction in e.g. the performance because of tolerance to the drug, and not necessarily drug abuse.

\section{CONCLUSION}

This study included participants from safety-critical positions in the offshore, shipping and aviation industries that were submitted to a workplace drug testing programme. In total, $2.9 \%$ of the samples were positive of one or more substances, which is a relatively low number compared to other studies in Norway, Europe and USA. Findings of illicit drugs were significantly associated with lower age. Decreasing trends in positive samples could be seen for opioids, while the positive findings for benzodiazepines and illegal drugs, especially amphetamines, were increasing. Although this is a special subset of the Norwegian work-force similar trends for changes in drug use could be expected in the general working populations.

\section{REFERENCES}

1. Verstraete A. Epidemiology of drug use in the working population. In: Verstraete A, ed. Workplace drug testing, 1 edn. London: Pharmaceutical Press, 2011: 1-33.

2. Drugs and Public Policy Group. Drug Policy and the Public Good: a summary of the book. Addiction 2010; 105 (7): 1137-1145.

3. Rehm J, Gnam W, Popova S, et al. The costs of alcohol, illegal drugs, and tobacco in Canada, 2002. J Stud Alcohol Drugs 2007; 68 (6): 886-895.

4. Raes E, Verstraete A. Effects of drugs on human performance. In: Verstraete A, ed. Workplace Drug Testing, 1 edn. London: Pharmaceutical Press, 2011: 35-69. 
5. Kazanga I, Tameni S, Piccinotti A, Floris I, Zanchetti G, Polettini A. Prevalence of drug abuse among workers: Strenghts and pitfalls of the recent Italian Workplace Drug Testing (WDT) legislation. Forensic Sci Int 2011 (In press).

6. Caplan Y, Goldberger B. Alternative specimens for workplace drug testing. J Anal Toxicol 2001; 25 (5): $396-$ 399.

7. Mieczkowski T. Urinanalysis and hair analysis for illicit drugs of driver applicants and drivers in the trucking industry. J Forensic Leg Med 2010; 17 (5): 254-260.

8. Pedersen-Bjergaard S, Rasmussen K. Omvendt-fase-kromatografi. In: Legemiddelanalyse. Bergen: Fagbokforlaget, 2004: 156-163.

9. Verstraete A, Pierce A. Workplace drug testing in Europe. Forensic Sci Int 2001; 121 (1-2): 2-6.

10. Gjerde H, Christophersen A, Moan I, et al. Use of alcohol and drugs by Norwegian employees: a pilot study using questionnaires and analysis of oral fluid. J Occup Med Toxicol 2010; 5 (13): 1-8.

11. Bush D. The U.S. Mandatory Guidelines for Federal Workplace Drug Testing Programs: Current status and future considerations. Forensic Sci Int 2008; 174 (2-3): 111-119.

12. Oral fluid reveals more heroin use than previously believed, according to Quest Diagnostics Drug Testing Index [http://www.questdiagnostics.com/employersolutions/dti/2011_01/dti.pdf]. August 23, 2011.

13. Presley L, Lehrer M, Seiter W, et al. High prevalence of 6-acetylmorphine in morphine-positive oral fluid specimens. Forensic Sci Int 2003; 133 (1-2): 22-25.

14. Gustavsen I, Al-Sammurraie M, Mørland J, Bramness J. Impairment related to blood drug concentrations of zopiclone and zolpidem compared to alcohol in apprehended drivers. Accid Anal Prev 2009; 41 462-466.

15. Kelly E, Darke S, Ross J. A review of drug use and driving: epidemiology, impairment, risk factors and risk perceptions. Drug Alcohol Rev 2004; 23 (3): 319-344.

16. Gjerde H, Normann PT, Pettersen BS, et al. Prevalence of alcohol and drugs among Norwegian motor vehicle drivers: a roadside survey. Accid Anal Prev 2008; 40 (5): 1765-1772.

17. Macdonald S, Hall W, Roman P, Stockwell T, Coghlan M, Nesvaag S. Testing for cannabis in the workplace: a review of the evidence. Addiction 2010; 105: 408-416.

18. Labat L, Fontaine B, Delzenne C, et al. Prevalence of psychoactive substances in truck drivers in the NordPas-de-Calais region (France). Forensic Sci Int 2008; 174 (2-3): 90-94.

19. EMCDDA. Annual report 2010: the state of the drugs problem in Europe - Cannabis prevalence and patterns of use [http://www.emcdda.europa.eu/online/annual-report/2010/cannabis/3]. November 16, 2011.

20. EMCDDA. Annual report 2010: the state of the drugs problem in Europe - Amphetamines, ecstasy and hallucinogenic substances Introduction [http://www.emcdda.europa.eu/online/annual-report/2010/amphetamines/1]. November 15, 2011.

21. EMCDDA. Annual report 2010: the state of the drugs problem in Europe - Amphetamines, ecstacy and hallucinogenic substances Prevalence and patterns of use [http://www.emcdda.europa.eu/online/annual-report/ 2010/amphetamines/3]. November 15, 2011.

22. Christophersen A, Mørland J. Drug analysis for control purposes in forensic toxicology. Workplace testing, sports medicine and related areas. Pharmacol Toxicol 1994; 74: 202-210. 